\title{
Hemodynamic impact of surgical correction of pectus excavatum - a cardiovascular magnetic resonance study
}

Anja Zagrosek ${ }^{1 *}$, Florian von Knobelsdorff-Brenkenhoff', Susanne Polleichtner², Klaus Schaarschmidt², Jeanette Schulz-Menger ${ }^{1}$

From 2011 SCMR/Euro CMR Joint Scientific Sessions

Nice, France. 3-6 February 2011

\section{Objectives}

The aim of the present study was to evaluate the impact of pectus excavatum-surgery on cardiac function with the use of cardiovascular magnetic resonance (CMR).

\section{Background}

It is unclear, whether the surgical repair of pectus excavatum $(\mathrm{PE})$ improves cardiovascular function or simply remains a cosmetic procedure. Previous studies with
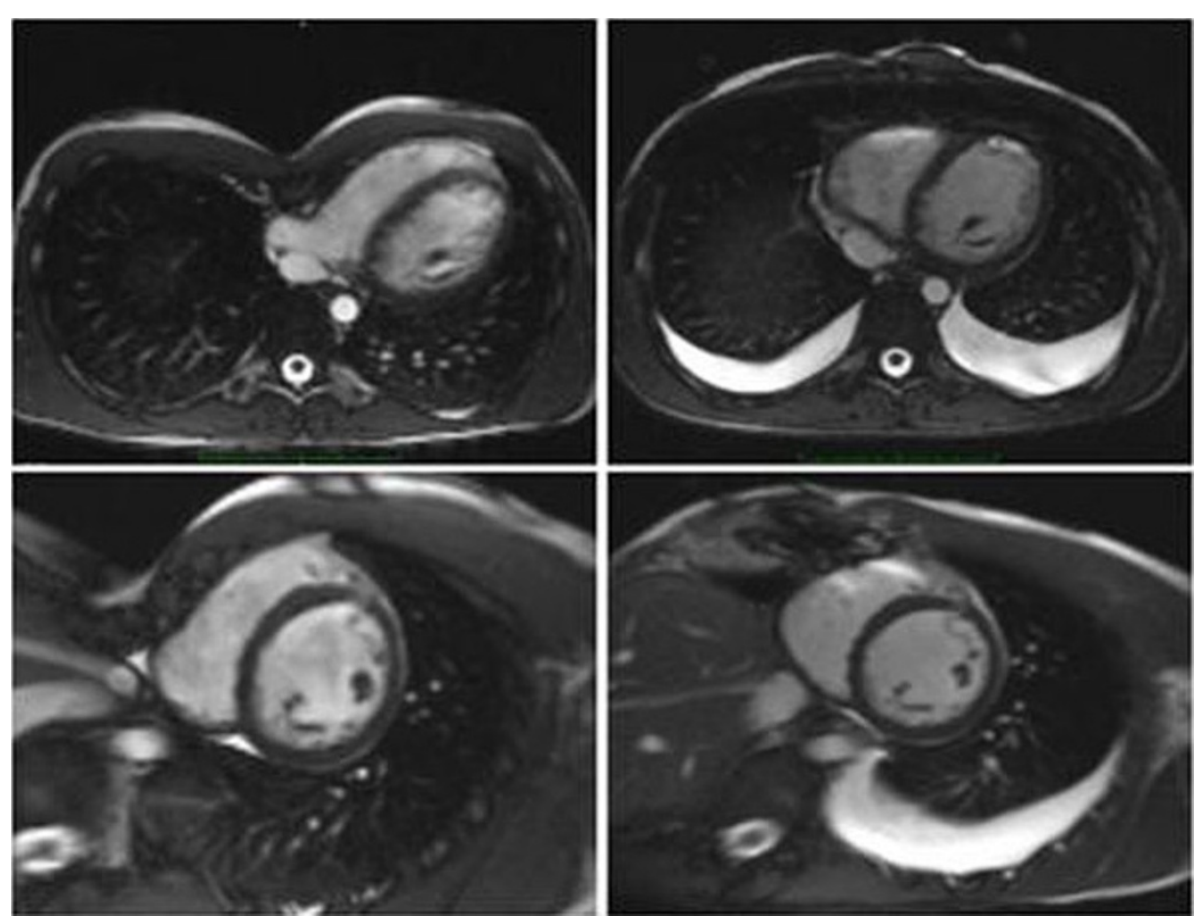

Figure 1 Upper row: Axial SSFP-images before (left) and after (right) surgery Lower row: Short axis SSFP-images before (left) and after (right) surgery.

${ }^{1}$ HELIOS Klinikum Berlin-Buch, Charité Campus-Buch, Humboldt University,

Berlin, Germany

Full list of author information is available at the end of the article 
Table 1 CMR parameters before and after surgery and at follow-up

\begin{tabular}{llllll}
\hline & Pre-op & Post-op & Pre-op vs. post-op P= & Follow-up (n=17) & Pre-op vs. follow-up P= \\
\hline LV-ejection fraction (\%) & $59.0 \pm 5.1$ & $62.5 \pm 3.4$ & $<0.001$ & $61.3 \pm 3.7$ & $<0.001$ \\
RV-ejection fraction (\%) & $47.0 \pm 5.3$ & $51.3 \pm 5.9$ & $<0.001$ & $50.1 \pm 3.9$ & $<0.001$ \\
LV-EDV (ml) & $158.5 \pm 32.5$ & $161.2 \pm 34.1$ & $\mathrm{~ns}$ & $155.4 \pm 30.1$ & $\mathrm{~ns}$ \\
RV-EDV (ml) & $203.6 \pm 38.7$ & $195.3 \pm 41.9$ & 0.047 & $189.1 \pm 32.9$ & $<0.001$ \\
LV-SV (ml) & $86.0 \pm 16.6$ & $92.4 \pm 15.0$ & 0.006 & $89.7 \pm 14.8$ & $\mathrm{~ns}$ \\
RV-SV (ml) & $90.6 \pm 18.8$ & $99.9 \pm 20.5$ & 0.001 & $93.9 \pm 13.7$ & $\mathrm{~ns}$ \\
Heart rate (bpm) & $77.1 \pm 12.3$ & $76.6 \pm 12.9$ & $\mathrm{~ns}$ & $72.3 \pm 11.8$ & $\mathrm{~ns}$ \\
\hline
\end{tabular}

legends: ns: not significant, LV: left ventricular, RV: right ventricular, EDV: enddiastolic volume, SV: stroke volume, bpm: beats per minute.

small sample sizes provided conflicting results. Therefore, health insurances currently refuse to pay for this intervention.

\section{Methods}

28 patients (age [mean \pm standard deviation] 21.1 \pm 8.6 years, 5 female, BMI $20.8 \pm 3.6 \mathrm{~kg} / \mathrm{m} 2$ ) scheduled for surgical correction of PE underwent CMR in a 1.5 T Scanner before and $9.7 \pm 1.4$ days after surgery (Nuss procedure: implantation of two transthoracical pectus bars). 17 patients returned for a follow up-CMR 95.8 \pm 20.2 days after surgery. Cardiac dimensions and function were assessed with cine-SSFP-imaging in short axis orientation for the left ventricle (LV) and for the right ventricle (RV) in axial orientation (imaging parameters: repetition time $2.9 \mathrm{~ms}$; echo time $1.2 \mathrm{~ms}$; flip angle $80^{\circ}$; field of view 340 to $380 \mathrm{~mm} 2$; matrix $256 \times 146$; bandwidth $930 \mathrm{~Hz} / \mathrm{px}$; 30 phases per R-R-interval, for LV: slice thickness $7 \mathrm{~mm}$; gap $3 \mathrm{~mm}$, and for RV: slice thickness $5 \mathrm{~mm}$; no gap). Phase contrast CMR (repetition time $38.9 \mathrm{~ms}$; echo time $2.8 \mathrm{~ms}$; flip angle $30^{\circ}$; field of view 219 x 319 mm; matrix 132 x 192; bandwidth 375 $\mathrm{Hz} / \mathrm{px}$; slice thickness $5.5 \mathrm{~mm}$ ) was used to assess RVand LV stroke volumes (SV). Figure 1.

\section{Results}

LV - and RV-ejection fraction increased significantly after surgery as well as at follow-up. LV-enddiastolic volume (LV-EDV) remained unchanged, whereas the RV-EDV decreased significantly after surgery. There was a tendency towards increased LV- and RV-stroke volumes after surgery and at follow up and towards a concurrently decreased heart rate (see table 1 for detailed results). All patients had bilateral pleural effusion after the intervention, which resolved almost entirely at follow up.

\section{Conclusion}

The findings of the present study suggest that surgical repair of pectus excavatum leads to changes in cardiac dimensions and function, contradicting the argument that this procedure is primarily cosmetic. Further studies with larger samples with inclusion of exercise tests are required.

Author details

${ }^{1}$ HELIOS Klinikum Berlin-Buch, Charité Campus-Buch, Humboldt University, Berlin, Germany. ${ }^{2}$ HELIOS Klinikum Berlin-Buch, Klinik für Kinderchirurgie, Berlin, Germany.

Published: 2 February 2011

doi:10.1186/1532-429X-13-S1-P190

Cite this article as: Zagrosek et al:: Hemodynamic impact of surgical correction of pectus excavatum - a cardiovascular magnetic resonance study. Journal of Cardiovascular Magnetic Resonance 2011 13(Suppl 1):P190.

Submit your next manuscript to BioMed Central and take full advantage of:

- Convenient online submission

- Thorough peer review

- No space constraints or color figure charges

- Immediate publication on acceptance

- Inclusion in PubMed, CAS, Scopus and Google Scholar

- Research which is freely available for redistribution

Submit your manuscript at www.biomedcentral.com/submit
C Biomed Central 